free diets were made, attempting to introduce fructose gradually, but with little success.

Dr. H. C. Knight and Sisters A. Court, E. Strange, C. Roberts, G. Crew, and M. Hood helped in the care of the children, and Miss S. Ward and Mr. J. B. Kiwanuka gave technical help. We are grateful to all of them, and to Professor R. A. McCance for his help in the preparation of this report.

Requests for reprints should be addressed to: Medical Research Council Infantile Malnutrition Research Unit, P.O. Box 7051, Kampala, Uganda.

\section{REFERENCES}

Anderson, C. M., Kerry, K. R., and Townley, R. R. W. (1965). Arch. Dis. Childh., 40, 1. Arthur, A. B., Clayton, B. E., Cottom, D. G., Seakins, J. W. T., and
Platt, J. W. (1966). Lancet, 1, 172.
Barker, S. B., and Summerson, W. H. (1941). F. biol. Chem., 138, 535. Bowie, M. D., Barbezat, G. O., and Hansen, J. D. L. (1967). Amer. f. clin. Nutr., 20, 89.

Bowie, M. D., Brinkman, G. L., and Hansen, J. D. L. (1965). F. Pediat., 66, 1083.

Cook, G. C., and Kajubi, S. K. (1966). Lancet, 1, 725.

Correa (1908). Rev. méd. Yucatan, 3, No. 6.

Dean, R. F. A. (1952). E. Afr. med. f., 29, 1 .

Galván, R. R., and Calderon, J. M. (1965). Amer. F. clin. Nutr., 16, 351.

James, W. P. T. (1968). Lancet, 1, 333.

Kahn, E. (1959). S. Afr. med. F., 33, 501.

Scragg, J., and Rubidge, C. (1960). Brit. med. f., 2, 1759.

Staff, T. H. E. (1968). East Afr. med. $¥$. In press.

Stanfield, J. P., Hutt, M. S. R., and Tunnicliffe, R. (1965). Lancet, 2, 519.

Viteri, F. E., Flores, J. M., and Behar, M. (1967). VII International Conference of Nutrition, Hamburg, vol. 4, p. 46, edited by J. Kühnan and H. D. Crerner, Oxford.

Wharton, B. A. (1968). In Protein Deficiencies and Calorie Deficiencies, edited by R. A. McCance and E. Widdowson. London. In press.

\title{
Sugar Intolerance in Malnourished Infants and Children
}

\author{
R. K. CHANDRA, ${ }^{*} \dagger$ M.D., F.C.C.P. ; R. R. PAWA,* M.B., B.S. ; O. P. GHAI,* M.D., D.C.H.
}

Brit. med.F., 1968, 4, 611-613

\begin{abstract}
Summary : Of 100 malnourished Indian infants and children 50 showed a stool pH below 6. Carbohydrate-loading tests demonstrated intolerance to lactose in 39 , to sucrose in 25 , and to maltose in 15 . D-Xylose absorption was reduced in 16. Steatorrhoea was detected in 7 of 18 children tested. Nutritional recovery reversed the abnormalities in all except four, in whom a primary enzymic deficiency was considered on the basis of persistent lactose intolerance and a positive family history.
\end{abstract}

\section{Introduction}

Diarrhoea is an almost inseparable component of the clinical picture of malnutrition, particularly kwashiorkor. With mounting evidence that infections and infestations do not have a primary role in its aetiology, diarrhoea was attributed to the various pathological changes of nutritional deficiency-fatty liver, atrophic pancreas, and thin-walled small intestine (Trowell et al., 1954). Dean (1957) originally suggested that the lactose of milk was the cause of severe diarrhoea encountered in cases of advanced kwashiorkor. Since then there have been sporadic reports of dissacharide intolerance in malnourished children (Cevini et al., 1962 ; Careddu et al., 1963 ; Bardare et al., 1965 ; Kerpel-Fronius et al., 1966. The largest series by Bowie et al. (1965) concerned 16 patients with acquired fermentative diarrhoea; oral carbohydrate-loading tests were done in only five cases. We present tolerance studies on 100 malnourished infants and children.

\section{Patients and Methods}

A group of 100 children, aged 3 months to 5 years, were diagnosed as suffering from protein-calorie malnutrition on the basis of their weight being below the 10th percentile of local standards for normal children, as shown in Fig. 1 (Ghai and Sandhu, 1968). Other physical signs such as loss of subcutaneous fat, light and sparse hair, sunken eyeballs, anaemia, and avitaminosis $\mathrm{A}$ and $\mathrm{B}$, were seen in varying degrees and

\footnotetext{
* Department of Paediatrics, All-India Institute of Medical Sciences, New Delhi 16.

† Present address, and for requests for reprints: Department of Immunology, Institute of Child Health, 30 Guilford Street, London W.C.1.
}

combinations. Oedema, hepatomegaly, and pigmentary skin changes were observed in seven children. The $p \mathrm{H}$ of the stools was determined by a narrow-range $p H$ paper. Patients with a faecal $p \mathrm{H}$ below 6 on three samples were studied further, as under.

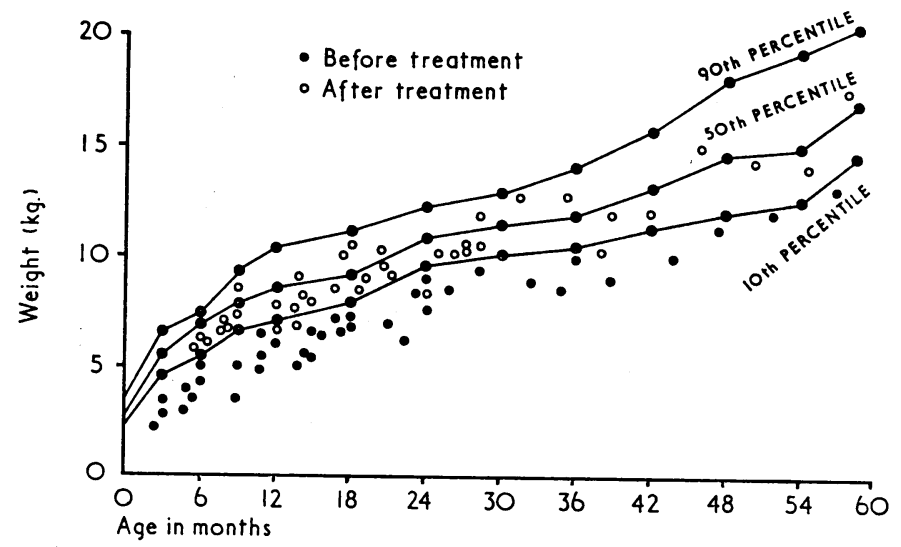

FIg. 1.-Weight distribution of patients initially and after nutritional recovery, plotted against curves for normal children (Ghai and Sandhu,

Carbohydrate tolerance tests were performed using lactose, sucrose, and maltose. Diarrhoea, if present, was controlled by using a diet low in disaccharides for a few days. After a fourhour fast the test substance was given orally in the dose of $2 \mathrm{~g} . / \mathrm{kg}$. body weight, as a $10 \%$ aqueous solution. Blood sugar was estimated by the Nelson-Somogyi method at 0, 30, 60, 90, and 120 minutes. Clinical symptoms developing during the test or within a few hours of it were noted. The absorption curve was thought to be flat if the maximal rise in blood sugar over fasting level was less than $30 \mathrm{mg} . / 100 \mathrm{ml}$. In that event the tolerance test was repeated, using the component monosaccharide/s as the loading substance-glucose and galactose in the case of lactose, glucose and fructose for sucrose, and glucose alone for maltose.

After an oral dose of $5 \mathrm{~g}$. of D-xylose its excretion in the urine was measured over a five-hour period by the method of Roe and Rice (1948). Values below $1 \mathrm{~g}$. were regarded as abnormal. Faecal fat was estimated by the method of van de 
Kamer et al. (1949). Stools were examined for the presence of enteropathogenic bacteria and ova/cysts of parasites.

The children were treated for a period of three months with a high-calorie protein-rich diet low in disaccharide sugars. The weight was recorded again and the carbohydrate-tolerance tests were repeated at the end of the three months. Other family members with symptoms suggestive of disaccharide malabsorption were studied.

\section{Results}

Of 100 malnourished children 50 had a faecal pH below 6 . Of these 50 patients 39 with acid stools showed an abnormal lactose-loading test ; 16 were intolerant to the component monosaccharides as well (Figs. 2 and 3). Among lactose-intolerant children 25 had a flat absorption curve on sucrose load (Fig. 4), and 15 on maltose load. During the course of the carbohydrate absorption tests about four-fifths of the intolerant children had obvious discomfort, abdominal distension, vomiting or diarrhoea, and the $\mathrm{pH}$ of the first stool passed after the procedure was consistently below 4 . The D-xylose test was abnormal in all the 16 children who had shown poor absorption of glucosegalactose (Fig. 2). Daily faecal fat excretion exceeded $6 \mathrm{~g}$. in 7 out of 18 children in whom it was estimated. No enteropathogenic organism was recovered from any patient; three showed cysts of Giardia lamblia and two of $H$. nana.

At the end of three months of dietary therapy all children showed nutritional recovery and had achieved an adequate gain in weight to cross the 10th percentile for their chronologic age (Fig. 1). Carbohydrate-tolerance tests done at this stage showed



FIG. 2.-Lactose loading tests before and after nutritional recovery.

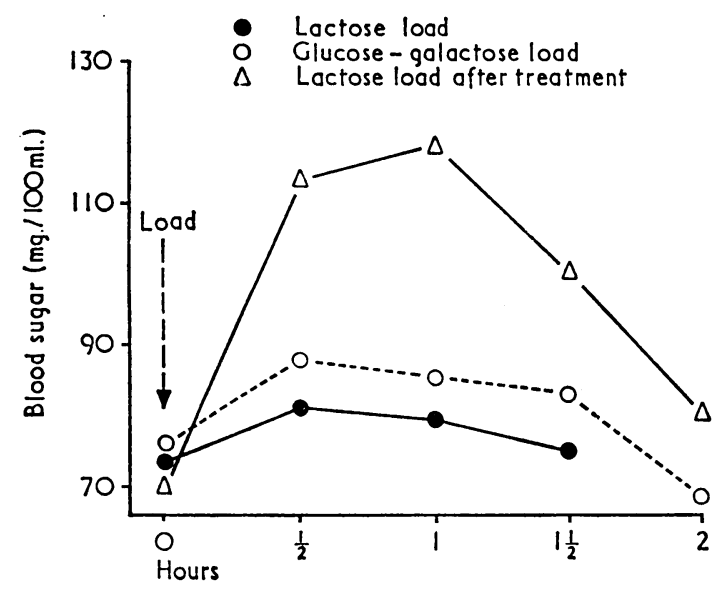

FIG. 3.-Lactose absorption test showing flat curves for the disaccharide as well as its components-glucose and galactose. normal absorption of the three disaccharides in all the patients (Figs. 2, 4, and 5) except four, who continued to be intolerant to lactose (Figs. 2 and 6). D-Xylose and fat absorption reverted to normal in all cases.

The four children with persistent lactose malabsorption were followed for periods of 5-11 months, and continued to show symptoms such as abdominal discomfort, diarrhoea, and mild distension whenever lactose was added to their diet. Two of

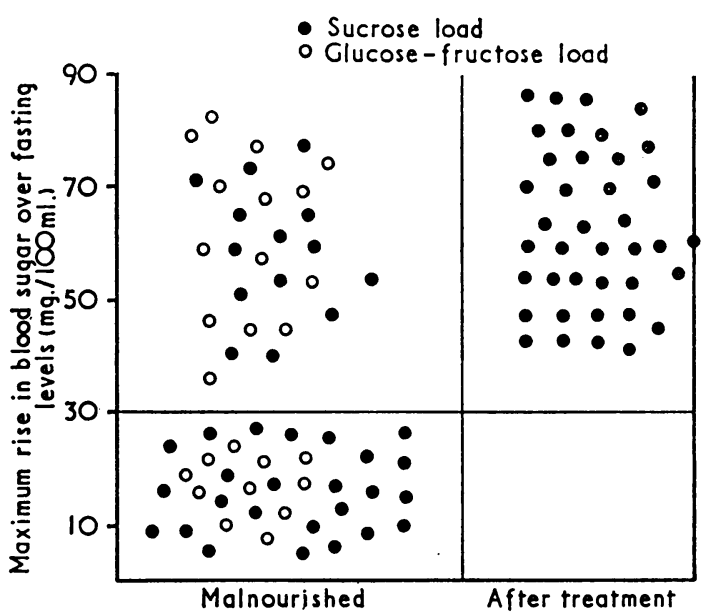

FIG. 4.-Sucrose loading tests before and after nutritional recovery.

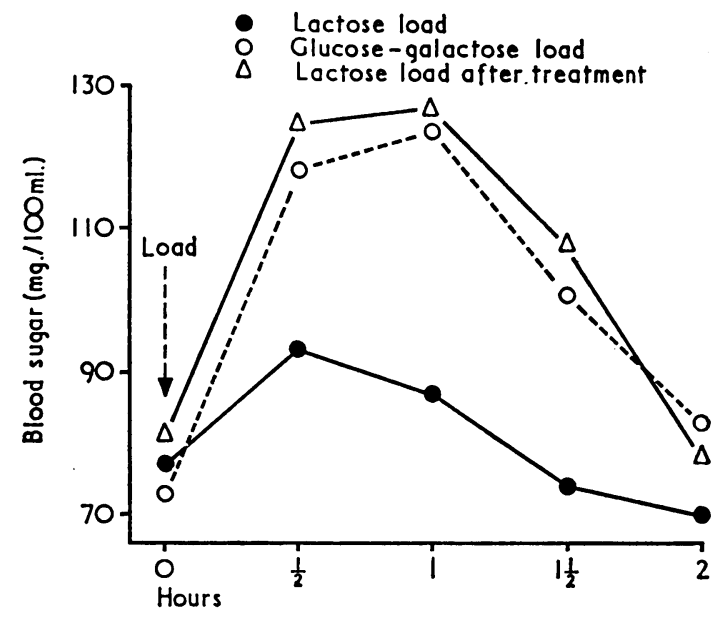

FIG. 5.-Lactose absorption test showing a flat curve initially which reverted to normal on correction of malnutrition.

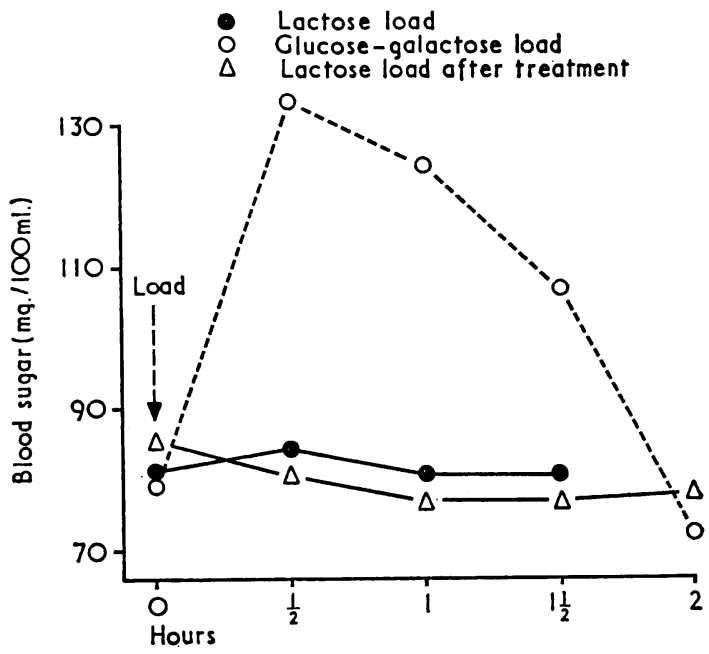

FIG. 6.-Lactose absorption test showing persistence of disaccharide intolerance. 
them are siblings, and their mother has proved symptomatic lactose intolerance. The father of another child gave a history of "being unable to digest milk," and a lactose absorption test yielded a flat curve. The fourth child has a persistent disaccharide and monosaccharide intolerance, and continues to get recurrent bouts of diarrhoea and has a poor weight gain.

\section{Discussion}

Carbohydrates in the form of polysaccharide starch and disaccharide sugars provide the bulk of calories in a normal diet. Each of these has to undergo enzymatic hydrolysis to monosaccharides before substantial absorption can occur. The enzymes involved in the process reside in the epithelial cells of small-intestinal mucosa, although their exact intracellular location-in the brush border alone or in the cytoplasm as wellis a subject of debate. The intestinal epithelium has the very rapid turnover rate of about 48 hours, and the superficially located enzymes are therefore very vulnerable to damage by a wide variety of noxious influences, thereby producing acquired disaccharidase deficiency (Laster and Ingelfinger, 1961; Townley, 1966). Lactase activity, which is normally lower than that of maltase and sucrase, gets hit first and most frequently. Lactose intolerance can thus occur without any significant alteration in the other enzymes. Lactase is also the last disaccharidase to recover (Kerpel-Fronius et al., 1966). Intestinal epithelial damage is a recognized result of protein-calorie malnutrition (Zubirán, 1961 ; Amin, 1966), enteropathogenic organisms, and intestinal parasites (Bowie et al., 1965 ; KerpelFronius et al., 1966).

The mechanism through which disaccharide intolerance produces diarrhoea is twofold. Unabsorbed sugar draws water into the lumen of the gut through osmosis, thereby acting as a cathartic with almost one-fifth the potency of magnesium sulphate. Unabsorbed sugar is also acted upon by colonic bacteria, resulting in the production of irritant low-molecularweight organic acids. Both these factors increase peristaltic activity and reduce transit time. The continued presence of unsplit sugars in the gut may damage the epithelial cells further (Holzel et al., 1962 ; Rey et al., 1963), perpetuating and aggravating the enzymic deficiency. These pathophysiological changes could be responsible for malabsorption of other substances, such as D-xylose and fat, as seen in the present study.
The diagnosis of disaccharide intolerance is made on the presence of acid stools, high faecal lactic acid, flat absorption curve, gastrointestinal symptoms on sugar load, and relief on exclusion of the offending carbohydrate. The stools are characteristically large, yellowish-green, frothy, rancid, loose, or watery, and contain shreds of fine mucus (Chandra et al., 1968). Enzyme assays on mucosal biopsies yield a wide range of values and are potentially fallacious because values are necessarily expressed as a function of the whole biopsy specimen rather than that of epithelial cells to which the enzymes are confined (Townley, 1966).

The persistence of lactose intolerance after nutritional recovery and its familial occurrence in three of the four patients in the present series suggests consideration of a primary enzymic defect with consequent diarrhoea and secondary malnutrition. All four patients were under 8 months of age, and their symptoms dated back to the postnatal period. In the fourth child there is a possibility of primary monosaccharide intolerance.

The study was supported in part by the Indian Council of Medical Research.

\section{REPERENCES}

Amin, K. (1966). Small Bowel Studies in Malnutrition and Hypoproteinemia. Thesis for M.D. New Delhi.

Bardare, M., Buitoni, P., and Careddu, P. (1965). Minerva pediat., 17, 832 .

Bowie, M. D., Brinkman, G. L., and Hansen, J. D. L. (1965). J. Pediat., 66, 1083 .

Careddu, P., Giovannini, M., and Cevini, G. (1963). Helv. paediat. Acta, 18, 97.

Cevini, G., Giovannini, M., and Careddu, P. (1962). Minerva pediat., 14,831 .

Chandra, R. K., Pawa, R. R., and Ghai, O. P. (1968). Indian f. med. Res. In press.

Dean, R. F. A. (1957). Mod. Probl. Paediat., 2, 133.

Ghai, O. P., and Sandhu, R. K. (1968). Indian Y. Pediat., 35, 91.

Holzel, A., Mereu, T., and Thomson, M. L. (1962). Lancet, 2, 1346.

Kerpel-Fronius, E., Jáni, L., and Fekete, M. (1966). Ann. paediat. (Basel), 206, 245 .

Laster, L., and Ingelfinger, F. J. (1961). New Engl. 7. Med., 264, 1138. Rey, J., Frézal, J., Jos, J., Bauche, P., and Lamy, M. (1963). Arch. tranc. pediat.", 20,381 .

Roe, J. H., and Rice, E. W. (1948). 7. biol. Chem., 173, 507.

Townley, R. R. W. (1966). Pediatrics, 38, 127.

Trowell, H. C., Davies, J. N. P., and Dean, R. F. A. (1954). Kwashiorkor. London.

van de Kamer, J. H., ten Bokkel Huinink, H., and Weyers, H. A. (1949). 7. biol. Chem., 177,347 .

Zubirán, S. (1961). Amer. 尹. dig. Dis., 6, 336.

\title{
Dependence on Hypnotic Drugs in General Practice
}

\author{
JOHN JOHNSON,* M.D., M.R.C.P.ED., D.P.M.; A. D. CLIFT, † M.B., M.R.C.G.P., D.R.C.O.G.
}

\begin{abstract}
Simmary : Of the patients in an industrial general practice $\mathbf{1 . 3 \%}$ required hypnotic drugs regularly. They were predominantly in the older age groups (mean 62.7 years), with an excess of widows. Only $0.02 \%$ were severely dependent; the remainder were mildly so, though they had been taking hypnotics for long periods (mean 5.6 years). There were three main original indications for hypnotics-namely, medical (pain), psychiatric, and onset insomnia in anxious personality disorder. Onefifth of the patients first took hypnotics while in hospital. The group as a whole manifested a high degree of abnormal psychological disposition.

It is suggested that many patients who take hypnotics regularly may be placebo reactors, and a more critical attitude to hypnotic prescribing is required both in hospital and in general practice.
\end{abstract}

Concern is repeatedly expressed about the steep rise in the consumption of hypnotic drugs, particularly barbiturates, during the past 15 years (Brit. med. F., 1965), and the fact that they constitute about one-fifth of all N.H.S. prescriptions (Brooke and Glatt, 1964). This has been reflected in the increase in incidents of self-poisoning by hypnotic drugs over the past 10 years (Kessel, 1965), and in the development of dependence on them (Bewley, 1968).

Mild and severe states of dependence on barbiturates are wellrecognized complications (Jaffe, 1965), but their incidence in the population and the degree of risk and frequency with which

\footnotetext{
* Senior Lecturer, University Department of Psychiatry, Manchester Royal Infirmary.

† General Practitioner, Middleton, Manchester.
} 